\title{
Nicotinamide mononucleotide supplementation enhances aerobic capacity in amateur runners: a randomized, double-blind study
}

Bagen Liao ${ }^{1 * \dagger} \mathbb{D}$, Yunlong Zhao ${ }^{2 \dagger}$, Dan Wang ${ }^{1,2}$, Xiaowen Zhang ${ }^{3}$, Xuanming $\mathrm{Hao}^{4}$ and Min $\mathrm{Hu}^{1}$

\begin{abstract}
Background: Recent studies in rodents indicate that a combination of exercise training and supplementation with nicotinamide adenine dinucleotide $\left(\mathrm{NAD}^{+}\right)$precursors has synergistic effects. However, there are currently no human clinical trials analyzing this.

Objective: This study investigates the effects of a combination of exercise training and supplementation with nicotinamide mononucleotide (NMN), the immediate precursor of $\mathrm{NAD}^{+}$, on cardiovascular fitness in healthy amateur runners.
\end{abstract}

Methods: A six-week randomized, double-blind, placebo-controlled, four-arm clinical trial including 48 young and middle-aged recreationally trained runners of the Guangzhou Pearl River running team was conducted. The participants were randomized into four groups: the low dosage group ( $300 \mathrm{mg} /$ day NMN), the medium dosage group (600 mg/day NMN), the high dosage group (1200 mg/day NMN), and the control group (placebo). Each group consisted of ten male participants and two female participants. Each training session was 40-60 min, and the runners trained 5-6 times each week. Cardiopulmonary exercise testing was performed at baseline and after the intervention, at 6 weeks, to assess the aerobic capacity of the runners.

Results: Analysis of covariance of the change from baseline over the 6 week treatment showed that the oxygen uptake $\left(\mathrm{VO}_{2}\right)$, percentages of maximum oxygen uptake $\left(\mathrm{VO}_{2 \mathrm{max}}\right.$, power at first ventilatory threshold, and power at second ventilatory threshold increased to a higher degree in the medium and high dosage groups compared with the control group. However, there was no difference in $\mathrm{VO}_{2 \max }, \mathrm{O}_{2}$-pulse, $\mathrm{VO}_{2}$ related to work rate, and peak power after the 6 week treatment from baseline in any of these groups.

Conclusion: NMN increases the aerobic capacity of humans during exercise training, and the improvement is likely the result of enhanced $\mathrm{O}_{2}$ utilization of the skeletal muscle.

Trial registration number: ChiCTR2000035138.

Keywords: Exercise training, NMN supplementation, Ventilatory threshold, Aerobic capacity

\footnotetext{
* Correspondence: bagen2015@163.com

${ }^{\dagger}$ Yunlong Zhao is joint first author. Yunglong Zhao and Bagen Liao have equal contributions.

${ }^{1}$ Department of Sports Medicine, Guangzhou Sport University, Guangzhou 510150, China

Full list of author information is available at the end of the article
}

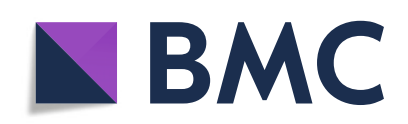

(- The Author(s). 2021 Open Access This article is licensed under a Creative Commons Attribution 4.0 International License, which permits use, sharing, adaptation, distribution and reproduction in any medium or format, as long as you give appropriate credit to the original author(s) and the source, provide a link to the Creative Commons licence, and indicate if changes were made. The images or other third party material in this article are included in the article's Creative Commons licence, unless indicated otherwise in a credit line to the material. If material is not included in the article's Creative Commons licence and your intended use is not permitted by statutory regulation or exceeds the permitted use, you will need to obtain permission directly from the copyright holder. To view a copy of this licence, visit http://creativecommons.org/licenses/by/4.0/. The Creative Commons Public Domain Dedication waiver (http://creativecommons.org/publicdomain/zero/1.0/) applies to the data made available in this article, unless otherwise stated in a credit line to the data. 


\section{Introduction}

Nicotinamide adenine dinucleotide $\left(\mathrm{NAD}^{+}\right)$is pivotal to physiological processes, not only as the coenzyme of cellular oxidation-reduction reactions but also for the activation of $\mathrm{NAD}^{+}$-consuming enzymes, such as sirtuins, poly-ADP-ribose polymerases (PARPs), cADP-ribose synthases, NADase (CD38), and mono-ADP-ribose transferases (ARTs) [1]. $\mathrm{NAD}^{+}$participates in more than $50 \%$ of all physiological processes, including mitochondrial biogenesis, cardiovascular protection, neuroprotection, oxidative stress, DNA damage repair, stem cell rejuvenation, and inflammation [2]. Low $\mathrm{NAD}^{+}$levels are associated with age-associated physical disability and diseases, such as metabolic syndrome and cardiovascular disease [1-3]. The $\mathrm{NAD}^{+}$salvage pathway, which utilizes $\mathrm{NAD}^{+}$precursors, is the predominant mechanism for maintaining cellular $\mathrm{NAD}^{+}$levels in rodents and humans [1]. Among a diverse range of $\mathrm{NAD}^{+}$precursors, nicotinamide riboside (NR) and nicotinamide mononucleotide (NMN), two forms of water-soluble vitamin $\mathrm{B}_{3}$, are the two that have been studied in a surge of $\mathrm{NAD}^{+}$precursor research in recent years due to their safety. Supplementation with NR and supplementation with NMN have shown a dose-dependent increase in cellular NAD ${ }^{+}$ levels in a variety of tissues in rodents and humans [46]. Accordingly, replenishment of depleted $\mathrm{NAD}^{+}$pools by NR (mainly at the dose of 300 or $400 \mathrm{mg} / \mathrm{kg} / \mathrm{d}$ in mice or rats) or NMN (mainly at doses of $100-500 \mathrm{mg} /$ $\mathrm{kg} / \mathrm{d}$ in mice) alleviates pathologic states in rodent models of age- or diet-induced decline in physical function, metabolic dysfunctions, neurodegenerative diseases, cardiomyopathy, and myocardial and cerebral ischemic injury $[2,6]$. In addition, NMN supplementation improves energy expenditure, physical activity, and neuronal function in a dose-dependent manner $[7,8]$. Nevertheless, clinical studies have shown that the effects of NR (dosages from $500 \mathrm{mg} / \mathrm{d}$ to $2000 \mathrm{mg} / \mathrm{d}$; durations of 1 day to 3 months) on skeletal muscle, cardiovascular function, and physical function in the elderly and obese are limited [4]. However, the $\mathrm{NAD}^{+}$precursor nicotinic acid (NA), an effective pharmacological drug with indications for lowering triacylglycerol levels and dilating blood vessels [9], significantly improved skeletal muscle function in healthy individuals [10] and in patients with adult-onset mitochondrial myopathy $[11,12]$. NR and NMN have many similar pharmacological effects, but they are also different in a number of aspects. For example, in contrast to NMN, NR was observed to be unstable in rodent plasma [13]. Furthermore, NMN improved cardiac function in patients with Friedreich's ataxia (FRDA) cardiomyopathy, whereas NR did not [14].

Regular exercise improves aerobic capacity, cardiovascular health, metabolic health, and physical function $[15$,
16], but many of such improvements may be $\mathrm{NAD}^{+} / \mathrm{sir}-$ tuins-related [17, 18]. Exercise training increases the expression of nicotinamide phosphoribosyltransferase (NAMPT), the rate-limiting enzyme in the $\mathrm{NAD}^{+}$salvage pathway, as well as the levels of $\mathrm{NAD}^{+}$and activity of sirtuins [19, 20]. Endurance athletes show a high NAMPT expression in skeletal muscle [21]. One study that used a mouse model of maternal obesity [22] reported that 18-day NMN injection and 9 weeks of exercise had similar benefits for reversing metabolic dysfunction and showed that NMN had stronger effects on hepatic fat metabolism than did exercise. Deletion of PARP-1 or CD38, or the inhibitor of CD38 or PARP-1, improves mitochondrial function and endurance performance in mice [23-25]. Furthermore, overexpression of muscle NAMPT in combination with exercise in wild-type mice augmented exercise endurance, maximum oxygen uptake $\left(\mathrm{VO}_{2} \mathrm{max}\right)$, and mitochondrial respiratory capacity compared with exercise training alone $[23,26]$. NR ( $400 \mathrm{mg} / \mathrm{kg} / \mathrm{d})$ and NMN $(500 \mathrm{mg} / \mathrm{kg} / \mathrm{d})$ with exercise training increased endurance performance in healthy young [27] and elderly [17] mice. Nevertheless, a decrease in endurance performance from NR $(300 \mathrm{mg} / \mathrm{kg} / \mathrm{d})$ in combination with swimming training was shown in young rats [28]. At present, the effect of the combination of exercise and NMN supplementation on cardiovascular fitness in healthy humans has not been reported. Cardiopulmonary exercise test (CPET) is the gold-standard method for assessing aerobic fitness. In this study, we conducted a six-week randomized, double-blind, four-arm, placebo-controlled clinical trial to investigate the effect of different doses of NMN supplementation on cardiovascular fitness.

\section{Methods \\ Subjects}

This study was performed at the Key Laboratory of Exercise and Health Promotion of Guangzhou Sport University and was approved by the ethics committee of Guangzhou Sport University (ethics approval number 2020 LCLL-003). Forty-eight healthy recreationally trained runners (40 males and 8 females, aged 27-50 years, with regular exercise years of $1-5$ years) from the Guangzhou Pearl River running team were recruited for the study. All participants were healthy and nonsmokers who did not drink caffeine or alcoholic drinks and had no prior use of medication or supplemental nutrients. Furthermore, all participants gave written informed consent to be included in the study before the initiation of the study.

\section{Study design}

The study was a double-blind, randomized controlled trial, and it is registered in the Chinese Clinical Trial 
Registry (ChiCTR2000035138 at http://www.chictr.org. $\mathrm{cn} /$ ). Participants were randomly assigned to one of four groups (each group included ten male participants and two female participants). Randomization was stratified for gender. Allocation to nutritional supplementation with NMN (treatment groups) or placebo (control group) was concealed to the participants, support staff, and investigators, except for the quality specialists, during the course of the study.

\section{Supplementation}

All of the participants were instructed to not change their habitual diet and daily living routines, and to refrain from caffeine during the study. The oral supplementation of powder (with or without NMN) lasted for 6 weeks. The lower dosage group received one bag with $150 \mathrm{mg}$ NMN powder twice daily (Bid), the medium dosage group received one bag with $300 \mathrm{mg}$ NMN powder Bid, the high dosage group received one bag with $600 \mathrm{mg}$ NMN powder Bid, and the control group received one bag with matching placebo powder containing no NMN Bid. The placebo powder was composed of cranberry powder and maltodextrin, and all bags with different NMN were identical in weight, size, shape, and color. All the materials, including the placebo powder, were provided by GeneHarbor (Hong Kong) Biotechnologies Ltd. Participants were asked to take their supplement (one bag at breakfast and one at lunch or in the afternoon) before training. To record the consumption count, any remaining bags were returned to the study supervisor to ensure compliance to the supplementation protocol every weekend and at the end of the study.

\section{Training}

All participants actively trained during the study period by adhering to an exercise program. The exercise program consisted of 6 weeks of aerobic exercise (running and cycling), with a single exercise session lasting 40-60 min. The exercise program called for 5-6 of these sessions per week. Furthermore, all participants were required to run 3-4 times per week and ride the bicycle twice per week. The exercise intensity was monitored by heart rate (HR) measurements based on the results of the CPET at baseline. The target HR ranges of exercise corresponded to $80-100 \% \mathrm{VO}_{2}\left(80-90 \% \mathrm{VO}_{2}\right.$ for cycling, $90-100 \% \mathrm{VO}_{2}$ for running) at first ventilatory threshold $\left(\mathrm{VT}_{1}\right)$ during the first 2 weeks, $90-110 \% \mathrm{VO}_{2}$ (90-100\% $\mathrm{VO}_{2}$ for cycling, $100-110 \% \mathrm{VO}_{2}$ for running) at $\mathrm{VT}_{1}$ during the middle 2 weeks, and $90-120 \% \mathrm{VO}_{2}$ (90-110\% $\mathrm{VO}_{2}$ for cycling, $100-120 \% \mathrm{VO}_{2}$ for running) at $\mathrm{VT}_{1}$ in the last 2 weeks. The training sessions were conducted in the afternoon or in the early evening on working days and in the morning on weekends. The target HR range was monitored by sports watch (Garmin
Forerunner 245) during exercise and study personnel supervised the training program throughout the study.

\section{Measurement of results}

All participants were evaluated by CPET at baseline and at the end of the six-week experimental intervention period. On testing day, participants came to the laboratory, which had a room temperature set between $20^{\circ} \mathrm{C}$ and $25^{\circ} \mathrm{C}$. Testing began at least $2.5 \mathrm{~h}$ after a normal meal, and participants could not have caffeine or alcohol for at least $12 \mathrm{~h}$ before the measurements.

\section{Anthropometric data}

Height and body mass were assessed by a height-weight meter. Body composition (body fat \%) and free-fat mass (FFM) were assessed by bioelectrical impedance analysis (Seca mBCA-115, Germany). Body mass index (BMI) was calculated as weight $(\mathrm{kg}) / \operatorname{Height}(\mathrm{m})^{2}$.

\section{Cardiopulmonary endurance performance}

Cardiopulmonary endurance performance was evaluated by CPET. The main measuring parameters include cardiovascular parameters $\left(\mathrm{VO}_{2}, \mathrm{O}_{2}\right.$-pulse, $\mathrm{VO}_{2}$-related to work rate), ventilatory parameter $\left(\mathrm{V}_{\mathrm{E}}\right)$, metabolic parameters (respiratory exchange ratio, $\mathrm{VT}_{1}$, and $\mathrm{VT}_{2}$ ) and exercise capacity parameters (workload and power). For the determination of above parameters, the participants were required to complete an incremental ramp exercise test until exhaustion was reached, as indicated on a cycloergometer (Ergoline ErgoSelect 200, Germany). For males, the starting workload was $50-100 \mathrm{~W}$, and there was a continuous increase of $20-30 \mathrm{~W}$ per minute. For females, the starting workload was $50-75 \mathrm{~W}$, and there was a continuous increase of $15-25 \mathrm{~W}$ per minute. The test was terminated when any three of the five following criteria were met: volitional fatigue, as indicated by an inability to maintain a set rate after verbal encouragement was given; HR failing to increase with the increasing workload; an increase in $\mathrm{VO}_{2}<150 \mathrm{~mL} / \mathrm{min}$ despite the workload increasing; a respiratory exchange ratio $($ RER) 21.10 ; a Borg rating of perceived exertion $>17$. The gas analyzer system was calibrated according to the manufacturer's recommendations before each test. In this test, a cardiorespiratory function test system (CORTEX MetaLyzer ${ }^{\circ} 3 B$, Germany) recorded the HR, heart rate reserve (HRR), RER, workload, power, oxygen consumption $\left(\mathrm{VO}_{2}\right)$, carbon dioxide production $\left(\mathrm{VCO}_{2}\right)$, expired minute volume $\left(\mathrm{V}_{\mathrm{E}}\right)$, partial pressure of end-tidal $\mathrm{O}_{2}\left(\mathrm{PETO}_{2}\right)$, and partial pressure of end-tidal $\mathrm{CO}_{2}$ $\left(\mathrm{PETCO}_{2}\right)$. A 12-lead electrocardiogram (ECG, Cardio 300 UBE00880, Germany) was continuously recording during the test. Blood pressure, including systolic blood pressure and diastolic blood pressure, was measured every 3 min during the cycling. 
Data collection and reduction

Measurements of the parameters $\left[\mathrm{VO}_{2 \max }, \mathrm{V}_{\mathrm{Emax}}\right.$, $\mathrm{HR}_{\max }$, HRR, peak workload, and peak power (metabolic equivalents, Mets)] were recorded according to the Clinician's Guide to Cardiopulmonary Exercise Testing statement [29]. $\mathrm{O}_{2}$-pulse, $\mathrm{VO}_{2}$ as a percentage of $\mathrm{VO}_{2 \max }$, and $\mathrm{VO}_{2}$ related to work rate $\left(\Delta \mathrm{VO}_{2} / \Delta \mathrm{WR}\right)$ were calculated (from beginning to $\mathrm{VT}_{1}$ ).

The $\mathrm{VT}_{1}$ is the first disproportionate increase in the rate of $\mathrm{VCO}_{2}$ compared with $\mathrm{VO}_{2}$; a significant increase in the $\mathrm{V}_{\mathrm{E}} / \mathrm{VO}_{2}$ without a concomitant increase in $\mathrm{V}_{\mathrm{E}} /$ $\mathrm{VCO}_{2}$; or an increase in the $\mathrm{PETO}_{2}$ with no simultaneous decrease in the $\mathrm{PETCO}_{2}$ [30]. The $\mathrm{VT}_{2}$, also called the respiratory compensation point, is the first disproportionate increase in $\mathrm{V}_{\mathrm{E}}$ compared with $\mathrm{VCO}_{2}$, the beginning increase in $\mathrm{V}_{\mathrm{E}} / \mathrm{VCO}_{2}$, or the beginning decrease in the $\mathrm{PETCO}_{2}[30]$.

\section{Statistical analysis}

The statistical analyses were carried out using SPSS 22.0. Baseline data are expressed as the mean and standard deviation. The differences between baseline data and post-intervention data are expressed as the mean and 95\% confidence interval (CI). Comparisons of the baseline data and post-intervention changes among the four groups were performed using oneway analysis of variance (ANOVA) followed by Tukey's post hoc test to identify significantly different means. ANOVA for repeated measurements of time course (pre- and post-intervention) and with or without NMN supplementation was also performed to defeat intergroup differences. In cases of a difference, the baseline measurement was used as the covariate in each covariance analysis. Cohen's $d$ was used to calculate effect sizes. An effect size of $\leq 0.2$ was considered as indicating a small clinical effect, 0.5 as indicating a moderate clinical effect, and $>0.8$ as indicating a large clinical effect [31]. Statistical significance was indicated by $p<0.05$.

\section{Results}

The combination of exercise and NMN does not change body mass or alter body composition

All participants completed the required intervention. The baseline characteristics are shown in Table 1 and Supplementary Table S1. There were no significant differences among the four groups. Following the 6 weeks NMN supplementation in amateur runners, differences in body mass, BMI, or body fat\% were found between the treatment groups and control group (Table 2).

\section{The combination of NMN and exercise increases VT but not $\mathrm{VO}_{2 \max }$ or $\mathrm{O}_{2-}$ pulse}

No significant changes in $\mathrm{HR}_{\max }, \mathrm{RER}_{\max }, \mathrm{HRR}, \mathrm{O}_{2^{-}}$ pulse, peak power, peak workload, $\Delta \mathrm{O}_{2} / \Delta \mathrm{WR}$, or $\mathrm{VO}_{2 \max }$ were shown between the control and any of the $\mathrm{NMN}$ treatment groups. However, the $\mathrm{VO}_{2} @ \mathrm{VT}_{1}$, \% $\mathrm{VO}_{2 \max } @ \mathrm{VT}_{1}, \quad \mathrm{HR} @ \mathrm{VT}_{1}, \quad$ power@VT ${ }_{1}$, and power@VT 2 (Tables S1 and S2; Table 3) were increased significantly from the NMN supplementation compared with baseline, and the positive effect was in a dosedependent manner (Table 4).

\section{Adverse events}

During the intervention period, all participants had taken the NMN or placebo according to the requirements, and none of the participants reported an adverse event. No obvious abnormalities were shown on the ECG during exercise in the CPET.

\section{Discussion}

In rodents, NMN is able to increase cellular $\mathrm{NAD}^{+}$content in dosage ranges from $31.25 \mathrm{mg} / \mathrm{kg} / \mathrm{d}$ to $500 \mathrm{mg} / \mathrm{kg} /$ $\mathrm{d}$, and it is shown to be safe $[2,6,22]$. In humans, only one study of this has been reported, which used a single dose of $500 \mathrm{mg}$ NMN. In this study, the NMN increased circulatory $\mathrm{NAD}^{+}$and was shown to be safe [32]. Here, we administrated three dosages (300, 600, and $1200 \mathrm{mg} /$ d) of NMN supplementation to healthy amateur runners during a 6-week exercise training program. The main

Table 1 Participant baseline characteristics, including age, exercise years, anthropometric data, and $\mathrm{VO}_{2 \mathrm{max}}$

\begin{tabular}{|c|c|c|c|c|c|c|}
\hline & total & control Group & Lower Dosage & Medium Dosage & High Dosage & $P$ value \\
\hline Age (years) & $35.6(6.1)$ & $36.1(6.0)$ & $37.0(5.7)$ & $35.5(6.1)$ & $33.5(6.6)$ & 0.54 \\
\hline Exercise years (years) & $2.8(1.4)$ & $2.7(1.5)$ & $2.6(1.4)$ & $2.9(1.4)$ & $2.8(1.3)$ & 0.94 \\
\hline Height (cm) & $168.4(6.1)$ & $171.7(6.3)$ & $166.9(5.1)$ & $169.0(6.2)$ & $166.3(6.3)$ & 0.14 \\
\hline Body mass (kg) & $62.5(8.6)$ & $64.9(8.1)$ & $62.0(8.7)$ & $62.5(11.3)$ & $60.7(6.1)$ & 0.69 \\
\hline $\mathrm{BMI}(\mathrm{kg} / \mathrm{m} 2)$ & $22.0(2.6)$ & $22.0(2.6)$ & $22.3(3.2)$ & $21.8(2.9)$ & $21.9(1.6)$ & 0.17 \\
\hline FFM (kg) & $52.0(7.5)$ & $53.4(7.2)$ & $52.2(7.1)$ & $52.5(8.4)$ & $50.0(7.5)$ & 0.16 \\
\hline Body fat $\%$ & $16.7(6.7)$ & $17.8(5.7)$ & $15.5(6.4)$ & $15.7(6.6)$ & $17.8(8.4)$ & 0.97 \\
\hline $\mathrm{VO}_{2 \max }((\mathrm{L} / \mathrm{min})$ & $2.48(0.49)$ & $2.64(0.46)$ & $2.54(0.52)$ & $2.43(0.45)$ & $2.34(0.52)$ & 0.56 \\
\hline
\end{tabular}

Note: Data in brackets represent means SD 
Table 2 Changes in body composition of the participants after the 6-week intervention

\begin{tabular}{lllllll}
\hline & Control Group & Lower Dosage & Medium Dosage & High Dosage & Time P value & T $\times \mathbf{D}$ P value \\
\hline$\Delta$ body mass $(\mathrm{kg})$ & $0.15(-0.42,0.72)$ & $0.07(-0.44,0.57)$ & $-0.05(-0.78,0.68)$ & $0.63(0.21,1.04)$ & 0.13 & 0.27 \\
$\Delta$ BMI $(\mathrm{kg} / \mathrm{m} 2)$ & $0.05(-0.14,0.25)$ & $0.03(-0.15,0.21)$ & $-0.02(-0.28,0.24)$ & $0.23(0.08,0.39)$ & 0.11 & 0.24 \\
$\Delta$ FFM $(\mathrm{kg})$ & $0.76(0.17,1.35)$ & $-0.24(-0.95,0.46)$ & $-0.02(-0.72,0.69)$ & $0.31(-0.23,0.85)$ & 0.13 & 0.09 \\
$\Delta$ body fat $(\%)$ & $-0.94(-2.11,0.24)$ & $0.47(-0.38,1.31)$ & $0.03(-1.04,1.08)$ & $0.16(-0.65,0.96)$ & 0.74 & 0.16 \\
\hline
\end{tabular}

Note: $\Delta$, The difference between pre and post intervention in mean $(95 \% \mathrm{Cl})$. ANOVA for repeated measurement for interaction of time (T) and dose (D)

finding of this study is that NMN supplementation during exercise improved first ventilatory threshold $\left(\mathrm{VT}_{1}\right)$ and power@ $\mathrm{VT}_{2}$ without changing the $\mathrm{VO}_{2 \max }$ and that this improvement was dose-dependent.

\section{Exercise combined with NMN did not change body composition}

Our observations indicate that six-week aerobic exercise with low- to high-dose NMN supplementation did not alter body mass, FFM, BMI, or body fat\%. Both NR [33] and NMN [7, 22] inhibited high-fat diet or age-induced weight gain and increased energy consumption in mice. A human study [34] of NR on body composition in healthy obese middle and older people showed that body fat \% improved, whereas body weight remained unchanged, and the improvement appeared to be a genderdependent. Exercise combined with NR showed no additional improvement in body weight reduction and fat deposits in young mice compared to exercise only [27]. Considering the good standing of BMI and body fat \% of the participants in this study, no further changes in BMI and body fat $\%$ were expected.

Exercise combined with NMN increases VT but not $\mathrm{VO}_{2 \max }$ A recent study on rodents demonstrated that exercise combined with NMN led to a further increase in running endurance in healthy young mice [17]. Our results specifically reveal that 6 weeks of endurance exercise combined with NMN supplementation in amateur runners enhanced $\mathrm{VT}_{1}, \mathrm{VO}_{2}$, and $\mathrm{VO}_{2 \max }$ but not $\mathrm{VO}_{2 \max }$, $\mathrm{V}_{\text {Emax }}, \mathrm{O}_{2}$-pulse, $\Delta \mathrm{O}_{2} / \Delta \mathrm{WR}, \mathrm{RER}$, or peak power. In addition, a large dose of NMN also improved the power@ $\mathrm{VT}_{2}$. These results indicate that NMN supplementation was able to further increase the ventilatory threshold compared to exercise alone. The improvement may be attributed to an improved ability of $\mathrm{O}_{2}$ utilization by skeletal muscle, as no changes in $\mathrm{VO}_{2 \max }$

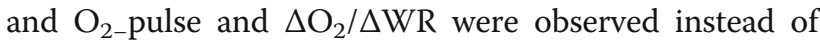
improvement of cardiac function. Our data suggest that skeletal muscle is one of the most sensitive tissues to NMN in humans.

Table 3 Changes in cardiopulmonary function of the participants after the 6-week intervention from baseline

\begin{tabular}{|c|c|c|c|c|c|c|}
\hline & control Group & Lower Dosage & Medium Dosage & High Dosage & Time $P$ value & $T \times D P$ value \\
\hline$\triangle \mathrm{O} 2$-pulse $\max (\mathrm{L} / \mathrm{min} / \mathrm{bpm})$ & $0.73(-0.23,1.68)$ & $1.25(0.23,2.27)$ & $0.82(0.07,1.70)$ & $1.17(0.32,2.02)$ & $<0.01$ & 0.56 \\
\hline$\triangle \mathrm{RER} \max$ & $0.09(0.00,0.18)$ & $-0.02(-0.07,0.07)$ & $0.05(-0.16,0.11)$ & $0.03(-0.08,0.14)$ & 0.04 & 0.36 \\
\hline$\Delta \dot{V} \mathrm{O}_{2 \max }(\mathrm{L} / \mathrm{min})$ & $0.18(0.02,0.36)$ & $0.23(0.09,0.37)$ & $0.26(1.74,0.35)$ & $0.32(0.20,0.43)$ & $<0.01$ & 0.48 \\
\hline$\triangle$ Peak power (Mets) & $0.72(-0.04,1.49)$ & $1.05(0.45,1.65)$ & $1.18(0.78,1.58)$ & $1.45(0.86,2.06)$ & $<0.01$ & 0.31 \\
\hline$\Delta$ Peak workload (W) & $10.9(-2.47,24.24)$ & $11.25(-0.43,22.93)$ & $13.58(5.44,21.7)$ & $13.93(8.92,18.95)$ & $<0.01$ & 0.58 \\
\hline$\Delta \mathrm{HR} @ \mathrm{VT} 1$ (bpm) & $5.8 \&(0.3,11.4)$ & $5.2 \&(1.1,9.2)$ & $12.8(7.8,17.8)$ & $16.0(10.4,21.5)$ & $<0.01$ & $<0.01$ \\
\hline$\Delta \mathrm{O} 2$-pulse @VT1 (L/min/bpm) & $0.55(-0.37,1.46)$ & $1.17(0.71,1.62)$ & $0.92(0.17,2.20)$ & $2.00(1.23,2.77)$ & $<0.01$ & 0.10 \\
\hline$\Delta \dot{V} \mathrm{O}_{2} @ \mathrm{VT} 1(\mathrm{~L} / \mathrm{min})$ & $0.17 \# \&(0.09,0.24)$ & $0.24 \&(0.18,0.30)$ & $0.33(0.25,0.41)$ & $0.47(0.34,0.60)$ & $<0.01$ & $<0.01$ \\
\hline APower @AVT1 (Mets) & $0.69 \# \&(0.35,1.03)$ & $1.06 \&(0.80,1.31)$ & $1.41 \&(1.02,1.79)$ & $2.13(1.56,2.69)$ & $<0.01$ & $<0.01$ \\
\hline$\Delta \% \dot{V} \mathrm{O}_{2 \max } @ \mathrm{VT} 1(\%)$ & $2.1 \&(-0.85,1.49)$ & $3.5 \&(0.05,7.00)$ & $6.5(3.62,9.43)$ & $10.3(7.61,13.05)$ & $<0.01$ & $<0.01$ \\
\hline$\Delta \mathrm{HR} @ \mathrm{VT} 2$ (bpm) & $5.6(1.9,9.4)$ & $6.7(3.2,10.2)$ & $10.8(4.5,17.2)$ & $12.4(4.4,20.5)$ & $<0.01$ & 0.23 \\
\hline$\Delta \mathrm{O} 2$-pulse @VT2 (L/min/bpm) & $0.55(-0.37,1.47)$ & $1.58(0.95,2.22)$ & $0.50(0.04,1.91)$ & $1.67(0.72,2.62)$ & $<0.01$ & 0.16 \\
\hline$\Delta \dot{\mathrm{V}} \mathrm{O}_{2} @ \mathrm{VT} 2(\mathrm{~L} / \mathrm{min})$ & $0.20(0.03,1.49)$ & $0.39(0.26,0.52)$ & $0.33(0.22,0.44)$ & $0.44(0.29,0.58)$ & $<0.01$ & 0.06 \\
\hline$\Delta$ Power @VT2 (Mets) & $0.78(0.07,1.49)$ & $1.78(1.20,2.35)$ & $1.56(1.00,2.11)$ & $2.04(1.34,2.73)$ & $<0.01$ & 0.03 \\
\hline$\Delta \% \dot{V} \mathrm{O}_{2 \max } @ \mathrm{VT} 2(\%)$ & $1.55(-1.75,4.84)$ & $6.67(3.20,10.10)$ & $4.25(1.28,7.22)$ & $6.58(3.57,9.59)$ & $<0.01$ & 0.06 \\
\hline$\Delta O 2 / \Delta W R$ slope $(\mathrm{ml} / \mathrm{min} / \mathrm{w})$ & $0.11(-0.58,0.79)$ & $0.44(-0.16,1.04)$ & $0.58(0.01,1.16)$ & $0.69(0.06,1.45)$ & $<0.01$ & 0.56 \\
\hline
\end{tabular}

Note: The difference of parameter between pre and post intervention among four groups were performed using one-way ANOVA. \#VS medium dosage, $P<0.05$, \&VS large dosage, $P<0.05$

ANOVA for repeated measurement for interaction of time $(T)$ and dose $(D)$. bpm, beat per minute 
Table 4 Analysis of the effect sizes (Cohen's d), expressed as the mean ( $95 \% \mathrm{Cl}$ ) and p value, for differences in adjusted means between the groups after the intervention

\begin{tabular}{|c|c|c|c|c|c|c|c|c|c|c|c|c|}
\hline & \multicolumn{2}{|c|}{ Lower VS control } & \multicolumn{2}{|c|}{ Medium VS control } & \multicolumn{2}{|c|}{ High VS control } & \multicolumn{2}{|c|}{ Medium VS Lower } & \multicolumn{2}{|c|}{ High VS Lower } & \multicolumn{2}{|c|}{ High VS Medium } \\
\hline & $\begin{array}{l}\mathrm{ES} \\
(95 \% \mathrm{Cl})\end{array}$ & $\begin{array}{l}P \\
\text { value }\end{array}$ & $\begin{array}{l}\mathrm{ES} \\
(95 \% \mathrm{Cl})\end{array}$ & $\begin{array}{l}P \\
\text { value }\end{array}$ & $\begin{array}{l}\text { ES } \\
(95 \% \mathrm{Cl})\end{array}$ & $\begin{array}{l}P \\
\text { value }\end{array}$ & $\begin{array}{l}\text { ES } \\
(95 \% \mathrm{Cl})\end{array}$ & $\begin{array}{l}P \\
\text { value }\end{array}$ & $\begin{array}{l}\text { ES } \\
(95 \% \mathrm{Cl})\end{array}$ & $\begin{array}{l}P \\
\text { value }\end{array}$ & $\begin{array}{l}\mathrm{ES} \\
(95 \% \mathrm{Cl})\end{array}$ & $\begin{array}{l}P \\
\text { value }\end{array}$ \\
\hline VO2@VT1 & 0.61 & 0.16 & 1.45 & $<0.01$ & 2.62 & $<0.01$ & 0.83 & 0.05 & 2.03 & $<0.01$ & 1.20 & 0.01 \\
\hline (L/min) & $-0.25,1.42$ & & $0.48,2.30$ & & $1.43,3.62$ & & $-0.03,1.63$ & & $0.99,2.93$ & & $0.30,2.03$ & \\
\hline \%VO2max@VT1 & 0.34 & 0.42 & 0.89 & 0.04 & 1.56 & 0.01 & 0.55 & 0.19 & 1.22 & 0.01 & 0.69 & 0.10 \\
\hline (\%) & $-0.50,1.15$ & & $0.00,1.71$ & & $0.58,2.45$ & & $-0.28,1.34$ & & $0.31,2.04$ & & $-0.16,1.49$ & \\
\hline HR@VT1 & 0.1 & 0.81 & 0.86 & 0.05 & 1.19 & 0.01 & 0.72 & 0.09 & 1.06 & 0.02 & 0.36 & 0.38 \\
\hline (bpm) & $-0.72,0.92$ & & $-0.02,1.68$ & & $0.26,2.03$ & & $-0.13,1.52$ & & $0.17,1.87$ & & $-0.46,1.15$ & \\
\hline Power @VT1 & 0.56 & 0.18 & 1.15 & 0.01 & 2.30 & $<0.01$ & 0.58 & 0.16 & 1.74 & $<0.01$ & 1.17 & 0.01 \\
\hline (Mets) & $-0.29,1.38$ & & $0.23,1.99$ & & $1.18,3.25$ & & $-0.25,1.38$ & & $0.75,2.61$ & & $0.27,1.99$ & \\
\hline Power@VT2 & 0.99 & 0.02 & 0.77 & 0.07 & 1.25 & 0.01 & 0.22 & 0.59 & 0.26 & 0.52 & 0.48 & 0.24 \\
\hline (Mets) & $0.09,1.82$ & & $-0.10,1.59$ & & $0.32,2.09$ & & $-0.59,1.01$ & & $-0.55,1.05$ & & $-0.35,1.27$ & \\
\hline
\end{tabular}

bpm beat per minute

It is well-known that endurance exercise increases aerobic capacity through improving mitochondrial function, vascular endothelium function, and capillary density of muscle, independent of age [35]. NMN administration had also been reported to improve mitochondrial function in various metabolic organs, including skeletal muscle [36, 37], to improve vascular endothelium function $[17,38]$, to promote neoangiogenesis and increase capillary density, blood flow, and soluble oxygen levels, and to switch skeletal muscle fibers to the more oxidative type in elderly or aged mice [17, 18]. These exercise-induced adaptive changes undoubtedly contribute by increasing the anaerobic threshold [39]. Exercise combined with NMN administration further increased exercise endurance and rebuilt the skeletal muscle capillary number and density to youthful levels in elderly mice, and it significantly increased the capillary/myofiber ratio in the quadriceps compared to NMN alone or exercise alone in young mice [17].

Although NMN supplementation improved endothelium function and reduced vessel wall stiffness in aged rodents [38] and restored cardiac function in cardiac pathologies, such as cardiomyopathy and ischemia/reperfusion (I/R) cardiac injury $[40,41]$, research shows that NMN supplementation does not affect cardiac function or cardiac capillary density in elderly mice [17]. Our results also indicate that exercise with NMN supplementation had no added effect on cardiac function in amateur runners.

\section{Dose-dependent relationship}

It was reported in mice that lower dosages of NMN (100 $\mathrm{mg} / \mathrm{kg} / \mathrm{d})$ were better compared with larger doses (300 $\mathrm{mg} / \mathrm{kg} / \mathrm{d}$ ) for body weight, body composition, insulin sensitivity, bone mineral density, and physical activity [7], and treatment with $62.5 \mathrm{mg} / \mathrm{kg} \mathrm{NMN}$ was better than that with $125-500 \mathrm{mg} / \mathrm{kg} \mathrm{NMN}$ for ischemia-induced brain damage [8]. Furthermore, a lower dose of NMN led to an improvement in female infertility with enhanced oocyte quality [42]. According to an equivalent surface area dose (mg/kg body weight) conversion, a human dose is approximately one-tenth of that for a mouse [7]. Therefore, 50,100 , and $200 \mathrm{mg} / \mathrm{kg} / \mathrm{d}$ of NMN for mice is approximately 300, 600, $1200 \mathrm{mg} / \mathrm{d}$ for humans of $60 \mathrm{~kg}$ body weight. In contrast, our human study showed that exercise combining with NMN supplementation increases VT in a dose-dependent and the large dose of NMN had better effect. Of note, we also measured physical function and the results show that exercise combined with NMN supplementation had no effect on grip strength, push-up, or sitand-reach compared with exercise only, but $600 \mathrm{mg} / \mathrm{d}$ NMN, not $1200 \mathrm{mg} / \mathrm{d}$ NMN, significantly improved single leg stance test results (Supplementary Tables S3-S5). In one study, it was reported that there was an overdose $\mathrm{NAD}^{+}$precursor reduced skeletal muscle NAMPT content through negative feedback [43]. All of these data suggest that for NMN, there may not exist as one-size-fits-all.

\section{Side effects}

Pharmacological dose of NA and nicotinamide (NAM) may result in painful flushing, liver damage and NAM exhibit sirtuin-inhibiting effects [44, 45], whereas NMN and NR exhibit better pharmacokinetic and pharmacological properties [17, 46-48]. In rodent, long-term NMN administration from 100 to $300 \mathrm{mg} / \mathrm{kg} / \mathrm{d}$ did not result in any obvious side effects [7]. In human, single oral dose ranging from 100 to $500 \mathrm{mg}$ NMN was safe and had no significant deleterious effects in healthy individual [32]. In this study, 300-1200 mg, a day, 6 week did not have any obvious adverse symptoms and abnormal ECG. 


\section{Limitations}

In this study, one limitation was conducted the CPET on a cycloergometer instead of a treadmill. Taking into account the modality including cycling and the advantages of a cycloergometer recording the ECG, we had chosen a cycloergometer. However, the running was the main form of modality, CPET on a treadmill ergometer would be a better way to assess aerobic fitness. In addition, it was reported that values of $\mathrm{VO}_{2 \max }$ and the $\mathrm{VT}$ in active runners or amateur triathletes were $\sim 10 \%$ higher on treadmill than cycle ergometry [49], thus we prescribed targed $\mathrm{HR}$ during running training corresponding to $100-120 \% \mathrm{VO}_{2}$ at $\mathrm{VT}_{1}$ measured in cycle ergometer. Nevertheless, the intensity prescription for running training in the context of our study subjects did not rule out bias because of individual differences of interchangeability between tests.

The second limitation was that the changes of blood lactate (especially blood lactate at the peakpower) was not simultaneously measured during CPET. NMN supplementation had been reported to reduce post-exercise blood lactate with improvement in endurance in mice [17]. Another research study showed that three-week swimming training combined NR administration (300 $\mathrm{mg} / \mathrm{kg} / \mathrm{d}$ ) reduced glucose concentration and maximal blood lactate accumulation in rats with a decrease in exercise endurance [27]. The measurement of blood lactate could provide another insight into the metabolic adaptations underlying the VT-improving effect.

Another limitation of the current investigation was separate female from male due to a limited number of female participants. Additional studies are needed to determine if there exist gender difference and improvement in vascular endothelium function, and whether the combination of NMN supplementation and exercise leads to increases in capillary density, blood flow, and mitochondrial function.

\section{Conclusion}

The results of this study reveal that exercise training combining with the supplementation of NMN further lift ventilatory threshold in amateur runners, the benefit is dose-dependent and muscle-related.

\section{What are the new findings}

- The combination of NMN supplementation and exercise further improves ventilatory threshold even among healthy young and middle-aged people.

-The improvement of aerobic capacity is in a dosagedependent, large dosage of NMN with exercise has better effects.

-The improvement is muscle, not cardiac, related.

\section{How might impact on clinical practice in the near future}

- NMN as adjunct treatment may help to improve performance during exercise training.

-Exercise training combining with NMN supplementation may be a novel and practical strategy to increase endurance performance of athletes.

\section{Supplementary Information}

The online version contains supplementary material available at https://doi. org/10.1186/s12970-021-00442-4

Additional file 1: Table S1. Baseline cardiopulmonary function parameters of the participants. Table S2. Changes in cardiopulmonary function after 6-week intervention from baseline. Table S3. Baseline results of the physical function test. Table S4. The change in the physical function test results at 6-week intervention from baseline. Table S5. Analysis of the effect sizes (Cohen's d), expressed as the mean $(95 \% \mathrm{Cl})$ and $p$ value, for differences in adjusted means between the groups after the intervention.

\section{Acknowledgements}

We gratefully acknowledge the contribution of professor Jun Wang (GeneHarbor (Hong Kong) Biotechnologies Ltd) to the research.

\section{Availability of supporting data}

The data sets used and/or analyzed during the current study are available from the corresponding author on reasonable request.

\section{Authors' contributions}

The quality control, Min Hu; Experimental design, Bagen Liao, Yunlong Zhao; The measurement of cardiovascular fitness performance and physical function, Yunlong Zhao and Dan Wang; Training supervision, Xuanming Hao, Yunlong Zhao; Supplementation supervision, Dan Wang; Data collections: Xiaowen Zhang; Manuscript, Revisions, Bagen Liao, Yunlong Zhao; Funding, Min Hu, Bagen Liao. All authors read and approved the final manuscript.

\section{Authors' information}

Bagen Liao, professor in sports medicine, head of the Department of Sports Medicine at Guangzhou Sport University.

Min Hu, professor in sports physiology, vice principal of Guangzhou Sport University.

Xuanming Hao,professor in sports physiology at the College of Physical Education, South China Normal University.

Xiaowen Zhang, researcher in sports training at Guangzhou Institute of Sports Science.

Yunlong Zhao, Phd student.

Dan Wang, graduate student.

Funding

This research was supported by Grant 2020YFC2002900 from The National Key Research and Development Program of China.

\section{Declarations}

Ethics approval and consent to participate

The study was approved by the ethical committee of Guangzhou Sport University (ethics approval number 2020 LCLL-003).

Consent for publication

Written informed consent for publication consent of their clinical details (included in the informed consent form) was obtained from the subjects. 


\section{Author details}

Department of Sports Medicine, Guangzhou Sport University, Guangzhou 510150, China. ${ }^{2}$ Guangdong Physical Fitness and Health Management Association, Guangzhou 510310, China. ${ }^{3}$ Guangzhou Institute of Sports Science, Guangzhou 510620, China. ${ }^{4}$ South China Normal University, Guangzhou 510631, China.

\section{Received: 22 December 2020 Accepted: 18 May 2021}

\section{Published online: 08 July 2021}

\section{References}

1. Covarrubias AJ, Perrone R, Grozio A, Verdin E. NAD ${ }^{+}$metabolism and its roles in cellular processes during ageing. Nat Rev Mol Cell Biol. 2021;22(2): 119-41. https://doi.org/10.1038/s41580-020-00313-x.

2. Yoshino J, Baur JA, Imai S. NAD ${ }^{+}$intermediates: the biology and therapeutic potential of NMN and NR. Cell Metab. 2018;27(3):513-28. https://doi.org/10.1 016/j.cmet.2017.11.002.

3. Clement J, Wong M, Poljak A, Sachdev P, Brady N. The plasma NAD metabolome is dysregulated in "normal" aging. Rejuvenation Res. 2019; 22(2):121-30. https://doi.org/10.1089/rej.2018.2077.

4. Custodero C, Saini SK, Shin MJ, Jeon YK, Christou DD, McDermott MM, et al. Nicotinamide riboside-a missing piece in the puzzle of exercise therapy for older adults? Exp Gerontol. 2020;137:110972. https://doi.org/10.1016/j. exger.2020.110972

5. Trammell SA, Schmidt MS, Weidemann BJ, et al. Nicotinamide riboside is uniquely and orally bioavailable in mice and humans. Nat Commun. 2016; 7(1):12948. https://doi.org/10.1038/ncomms12948.

6. Hong W, Mo F, Zhang Z, Huang M, Wei X. Nicotinamide mononucleotide: a promising molecule for therapy of diverse diseases by targeting $\mathrm{NAD}^{+}$ metabolism. Front Cell Dev Biol. 2020;8:246. https://doi.org/10.3389/fcell.202 0.00246 .

7. Mills KF, Yoshida S, Stein LR, Grozio A, Kubota S, Sasaki Y, et al. Long-term administration of nicotinamide mononucleotide mitigates age-associated physiological decline in mice. Cell Metab. 2016;24(6):795-806. https://doi. org/10.1016/j.cmet.2016.09.013.

8. Park JH, Long A, Owens K, Kristian T. Nicotinamide mononucleotide inhibits post-ischemic $\mathrm{NAD}(+)$ degradation and dramatically ameliorates brain damage following global cerebral ischemia. Neurobiol Dis. 2016;95:102-10. https://doi.org/10.1016/j.nbd.2016.07.018.

9. Connell NJ, Houtkooper PH, Schrauwen P. NAD ${ }^{+}$metabolism as a target for metabolic health: have we found the silver bullet? Diabetologi. 2019:62(6): 888-99. https://doi.org/10.1007/s00125-019-4831-3.

10. Kaplon RE, Gano LB, Seals DR. Vascular endothelial function and oxidative stress are related to dietary niacin intake among healthy middle-aged and older adults. J Appl Physiol. 2014;116(2):156-63. https://doi.org/10.1152/ja pplphysiol.00969.2013.

11. Pirinen $E$, Auranen $M$, Khan NA, Brilhante $V$, Urho N, Pessia A, et al. Niacin cures systemic NAD + deficiency and improves muscle performance in adult-onset mitochondrial myopathy. Cell Metab. 2020;31(6):1078-90. https://doi.org/10.1016/j.cmet.2020.04.008.

12. Ringseis R, Gessner DK, Beer AM, Albrecht $Y$, Wen G, Most E, et al. Nicotinic acid improves endurance performance of mice subjected to treadmill exercise. Metabolites. 2020;10(4):138. https://doi.org/10.3390/metabo1004 0138.

13. Ratajczak J, Joffffraud M, Trammell SA, Ras R, Canela N, Boutant M, et al. NRK1 controls nicotinamide mononucleotide and nicotinamide riboside metabolism in mammalian cells. Nat Commun. 2016;7(1):13103. https://doi. org/10.1038/ncomms13103.

14. Martin AS, Abraham DM, Hershberger KA, Bhatt DP, Mao L, Cui H, et al. Nicotinamide mononucleotide requires SIRT3 to improve cardiac function and bioenergetics in a Friedreich's ataxia cardiomyopathy model. JCl Insight. 2017;2(14):e93885.

15. Milanovic Z, Sporis G, Weston M. Effectiveness of high-intensity interval training $(\mathrm{HIT})$ and continuous endurance training for VO2max improvements: a systematic review and meta-analysis of controlled trials. Sports Med. 2015; 45(10):1469-148. https://doi.org/10.1007/s40279-015-0365-0.

16. Pinckard K, Baskin KK, Stanford Kl. Effects of exercise to improve cardiovascular health. Front Cardiovasc Med. 2019;6:69. https://doi.org/10.33 89/fcvm.2019.00069.

17. Das A, Huang GX, Bonkowski MS, Longchamp A, Li C, Schultz MB, et al. Impairment of an endothelial $\mathrm{NAD}(+)-\mathrm{H} 2 \mathrm{~S}$ signaling network is a reversible cause of vascular aging. Cell. 2018;173(1):74-89. https://doi.org/10.1016/j. cell.2018.02.008

18. Zhang H, Ryu D, Wu Y, Gariani K, Wang X, Luan P, et al. NAD repletion improves mitochondrial and stem cell function and enhances life span in mice. Science. 2016;352(6292):1436-43. https://doi.org/10.1126/science.aaf2 693.

19. de Guia RM, Agerholm M, Nielsen TS, Consitt LA, Søgaard D, Helge JW, et al Aerobic and resistance exercise training reverses age-dependent decline in NAD+ salvage capacity in human skeletal muscle. Physiol Rep. 2019;7(12): e14139. https://doi.org/10.14814/phy2.14139.

20. Lamb DA, Moore JH, Mesquita PHC, Smith MA, Vann CG, Osburn SC, et al. Resistance training increases muscle $\mathrm{NAD}^{+}$and $\mathrm{NADH}$ concentrations as well as NAMPT protein levels and global sirtuin activity in middle-aged, overweight, untrained individuals. Aging (Albany NY). 2020;12(10):9447-60. https://doi.org/10.18632/aging.103218.

21. Costford SR, Bajpeyi S, Pasarica M, Albarado DC, Thomas SC, Xie H, et al. Skeletal muscle NAMPT is induced by exercise in humans. Am J Phys Endocrinol Metab. 2010;298(1):E117-26. https://doi.org/10.1152/ajpendo. 00318.2009

22. Uddin GM, Youngson NA, Doyle BM, Sinclair DA, Morris MJ. Nicotinamide mononucleotide (NMN) supplementation ameliorates the impact of maternal obesity in mice: comparison with exercise. Sci Rep. 2017;7(1): 15063. https://doi.org/10.1038/s41598-017-14866-z.

23. Brouwers B, Stephens NA, Costford SR, Hopf ME, Ayala JE, Yi F, et al. Elevated nicotinamide phosphoribosyl transferase in skeletal muscle augments exercise performance and mitochondrial respiratory capacity following exercise training. Front Physiol. 2018;9:704. https://doi.org/10.33 89/fphys.2018.00704.

24. Pirinen E, Canto C, Jo YS, Morato L, Zhang H, Menzies KJ, et al. Pharmacological inhibition of poly (ADP-ribose) polymerases improves fitness and mitochondrial function in skeletal muscle. Cell Metab. 2014;19(6): 1034-41. https://doi.org/10.1016/j.cmet.2014.04.002.

25. Tarrago MG, Chini CCS, Kanamori KS, Warner GM, Caride A, de Oliveira GC et al. A potent and specific CD38 inhibitor ameliorates age-related metabolic dysfunction by reversing tissue NAD+ decline. Cell Metab. 2018; 27(5):1081-95. https://doi.org/10.1016/j.cmet.2018.03.016.

26. Costford SR, Brouwers B, Hopf ME, Sparks LM, Dispagna M, Gomes AP, et al. Skeletal muscle overexpression of nicotinamide phosphoribosyl transferase in mice coupled with voluntary exercise augments exercise endurance. Mol Metab. 2018;7:1-11. https://doi.org/10.1016/j.molmet.2017.10.012.

27. Crisol BM, Veiga CB, Braga RR, Lenhare L, Baptista IL, Gaspar RC, et al. NAD(+ ) precursor increases aerobic performance in mice. Eur J Nutr. 2020;59(6): 2427-37. https://doi.org/10.1007/s00394-019-02089-z.

28. Kourtzidis IA, Dolopikou CF, Tsiftsis AN, Margaritelis NV, Theodorou AA, Zervos $\mid A$, et al. Nicotinamide riboside supplementation dysregulates redox and energy metabolism in rats: implications for exercise performance. Exp Physiol. 2018;103(10):1357-66. https://doi.org/10.1113/EP086964.

29. Nichols S, Taylor C, Ingle L. A clinician's guide to cardiopulmonary exercise testing 2: test interpretation. Br J Hosp Med. 2015;76(5):281-9. https://doi. org/10.12968/hmed.2015.76.5.281.

30. Cerezuela-Espejo V, Courel-Ibáñez J, Morán-Navarro R, Martínez-Cava A Pallarés JG. The relationship between lactate and Ventilatory thresholds in runners: validity and reliability of exercise test performance parameters. Front Physiol. 2018;9:1320. https://doi.org/10.3389/fphys.2018.01320.

31. Cohen J. Statistical power analysis for the behavioral sciences. Hillsdale: Erlbaum Associates; 1988.

32. Irie J, Inagaki E, Fujita M, Nakaya H, Mitsuishi M, Yamaguchi S, et al. Effect of oral administration of nicotinamide mononucleotide on clinical parameters and nicotinamide metabolite levels in healthy Japanese men. Endocr.J. 2020;67(2):153-60. https://doi.org/10.1507/endocrj.EJ19-0313.

33. Canto C, Houtkooper RH, Pirinen E, Youn DY, Oosterveer MH, Cen Y, et al. The $\mathrm{NAD}(+)$ precursor nicotinamide riboside enhances oxidative metabolism and protects against high-fat diet-induced obesity. Cell Metab. 2012;15(6):838-47. https://doi.org/10.1016/j.cmet.2012.04.022.

34. Remie CME, Roumans KHM, Moonen MPB, Connell NJ, Havekes B, Mevenkamp J, et al. Nicotinamide riboside supplementation alters body composition and skeletal muscle acetylcarnitine concentrations in healthy obese humans. Am J Clin Nutr. 2020;112(2):413-26. https://doi.org/10.1093/a $\mathrm{jcn} / \mathrm{nqaa072.}$

35. Hackney AC. Molecular and physiological adaptations to endurance training In: Schumann M, Rønnestad B, editors. Concurrent aerobic and strength 
training. Cham: Springer; 2019. p. 19-34. https://doi.org/10.1007/978-3-31975547-2_3.

36. Cerutti R, Pirinen E, Lamperti C, Marchet S, Sauve AA, Li W, et al. NAD (+)-dependent activation of Sirt1 corrects the phenotype in a mouse model of mitochondrial disease. Cell Metab. 2014;19(6):1042-9. https://doi.org/10.1 016/j.cmet.2014.04.001.

37. Gomes AP, Price NL, Ling AJ, Moslehi JJ, Montgomery MK, Rajman L, et al. Declining $N A D(+)$ induces a pseudohypoxic state disrupting nuclearmitochondrial communication during aging. Cell. 2013;155(7):1624-38 https://doi.org/10.1016/j.cell.2013.11.037.

38. de Picciotto NE, Gano LB, Johnson LC, Martens CR, Sindler AL, Mills KF, et al. Nicotinamide mononucleotide supplementation reverses vascular dysfunction and oxidative stress with aging in mice. Aging Cell. 2016;15(3): 522-30. https://doi.org/10.1111/acel.12461.

39. Duscha BD, Kraus WE, Jones WS, Robbins JS, Piner LW, Huffman KF, et al Skeletal muscle capillary density is related to anaerobic threshold and claudication in peripheral artery disease.Vascular Med. 2020; 1358863X20945794.doi: https://doi.org/10.1177/1358863X20945794

40. Diguet N, Trammell SAJ, Tannous C, Deloux R, Piquereau J, Mougenot N, et al. Nicotinamide riboside preserves cardiac function in a mouse model of dilated cardiomyopathy. Circulation. 2018;137(21):2256-73. https://doi.org/1 0.1161/CIRCULATIONAHA.116.026099.

41. Ryu D, Zhang H, Ropelle ER, Sorrentino V, Mazala DA, Mouchiroud L, et al. $N A D^{+}$repletion improves muscle function in muscular dystrophy and counters global PARylation. Sci Transl Med. 2016;8:361ra139.

42. Bertoldo MJ, Listijono DR, Ho WJ, Riepsamen AH, Goss DM, Richani D, et al. $\mathrm{NAD}(+)$ repletion rescues female fertility during reproductive aging. Cell Rep. 2020;30(6):1670-81. https://doi.org/10.1016/j.celrep.2020.01.058.

43. Dollerup OL, Chubanava S, Agerholm M, Sondergard SD, Altintas A, Moller $A B$, et al. Nicotinamide riboside does not alter mitochondrial respiration, content or morphology in skeletal muscle from obese and insulin-resistant men. J Physiol. 2020;598(4):731-54. https://doi.org/10.1113/JP278752.

44. Di Stefano M, Nascimento-Ferreira I, Orsomando G, Mori V, Gilley J, Brown R, et al. A rise in NAD precursor nicotinamide mononucleotide (NMN) after injury promotes axon degeneration. Cell Death Differ. 2015;22(5):731-42. https://doi.org/10.1038/cdd.2014.164.

45. Bogan KL, Brenner C. Nicotinic acid, nicotinamide, and nicotinamide riboside: a molecular evaluation of $\mathrm{NAD}^{+}$precursor vitamins in human nutrition. Annu Rev Nutr. 2008;28(1):115-30. https://doi.org/10.1146/a nnurev.nutr.28.061807.155443.

46. Martens CR, Denman BA, Mazzo MR, Armstrong ML, Reisdorph N, McQueen $M B$, et al. Chronic nicotinamide riboside supplementation is well-tolerated and elevates $\mathrm{NAD}^{+}$in healthy middle-aged and older adults. Nat Commun. 2018;9(1):1286. https://doi.org/10.1038/s41467-018-03421-7.

47. Elhassan YS, Kluckova K, Fletcher RS, Schmidt M, Garten A, Doig C, et al. Nicotinamide riboside augments the aged human skeletal muscle NAD metabolome and induces transcriptomic and anti-inflammatory signatures. Cell Rep. 2019;28(7):1717-28. https://doi.org/10.1016/..celrep.2019.07.043.

48. Fletcher RS, Lavery GG. The emergence of the nicotinamide riboside kinases in the regulation of $\mathrm{NAD}^{+}$metabolism. J Mol Endocrinol. 2018;61(3):R10721. https://doi.org/10.1530/JME-18-0085.

49. Millet GP, Vleck VE, Bentley DJ. Physiological differences between cycling and running: lessons from triathletes. Sports Med. 2009;39(3):179-206. https://doi.org/10.2165/00007256-200939030-00002.

\section{Publisher's Note}

Springer Nature remains neutral with regard to jurisdictional claims in published maps and institutional affiliations.

Ready to submit your research? Choose BMC and benefit from:
- fast, convenient online submission
- thorough peer review by experienced researchers in your field
- rapid publication on acceptance
- support for research data, including large and complex data types
- gold Open Access which fosters wider collaboration and increased citations
- maximum visibility for your research: over 100M website views per year
At BMC, research is always in progress.
Learn more biomedcentral.com/submissions

